\title{
Docosahexaenoic acid improves altered mineralization proteins, the decreased quality of hydroxyapatite crystals and suppresses oxidative stress induced by high glucose
}

\author{
SAÚL ERNESTO CIFUENTES-MENDIOLA ${ }^{1}$, LETICIA MORENO-FIERROS ${ }^{2}$, \\ PATRICIA GONZÁLEZ-ALVA ${ }^{3}$ and ANA LILIA GARCÍA-HERNÁNDEZ ${ }^{1}$
}

\author{
${ }^{1}$ Laboratory of Dental Research, Section of Osteoimmunology and Oral Immunology, FES Iztacala, \\ National Autonomous University of Mexico, San Sebastián Xhala, Cuautitlán Izcalli 54714; \\ ${ }^{2}$ Laboratory of Mucosal Immunity, FES Iztacala, National Autonomous University of Mexico, \\ Los Reyes Iztacala, Tlalnepantla 54090; ${ }^{3}$ Laboratory of Tissue Bioengineering, Dentistry Faculty, \\ National Autonomous University of Mexico, University City, Mexico City 04510, Mexico
}

Received September 29, 2021; Accepted December 30, 2021

DOI: $10.3892 / \mathrm{etm} .2022 .11160$

\begin{abstract}
Patients with type 2 diabetes mellitus (DM2) experience an increased risk of fractures and a variety of bone pathologies, such as osteoporosis. The suggested mechanisms of increased fracture risk in DM2 include chronic hyperglycaemia, which provokes oxidative stress, alters bone matrix, and decreases the quality of hydroxyapatite crystals. Docosahexaenoic acid (DHA), an omega-3 fatty acid, can increase bone formation, reduce bone loss, and it possesses antioxidant/anti-inflammatory properties. The present study aimed to determine the effect of DHA on altered osteoblast mineralisation and increased reactive oxygen species (ROS) induced by high glucose concentrations. A human osteoblast cell line was treated with $5.5 \mathrm{mM}$ glucose $(\mathrm{NG})$ or $24 \mathrm{mM}$ glucose $(\mathrm{HG})$, alone or in combination with 10 or $20 \mu \mathrm{M}$ DHA. The collagen type 1 (Col1) scaffold, the expression of osteocalcin (OCN) and bone sialoprotein type-II (BSP-II), the alkaline phosphatase (ALP) specific activity, the mineral quality, the production of ROS and the mRNA expression of nuclear factor erythroid 2-related factor-2 (NRF2) were analysed. Osteoblasts cultured in HG and treated with either DHA concentration displayed an improved distribution of the Col1 scaffold, increased OCN and BSP-II expression, increased NRF2 mRNA, decreased ALP activity, carbonate substitution and reduced ROS production compared with osteoblasts
\end{abstract}

Correspondence to: Dr Ana Lilia García-Hernández, Laboratory of Dental Research, Section of Osteoimmunology and Oral Immunology, FES Iztacala, National Autonomous University of Mexico, Jiménez Gallardo Avenue, San Sebastián Xhala, Cuautitlán Izcalli 54714, Mexico

E-mail: ana.garcia@unam.mx

Key words: docosahexaenoic acid, omega 3, bone quality, diabetic osteopathy, bone mineral matrix cultured in HG alone. DHA counteracts the adverse effects of HG on bone mineral matrix quality and reduces oxidative stress, possibly by increasing the expression of NRF2.

\section{Introduction}

Diabetes mellitus type 2 (DM2) is a chronic metabolic disease characterised by hyperglycaemia caused by an absolute or relative deficiency of insulin or insulin resistance (1). Its prevalence is increasing worldwide, and it is currently considered a worldwide epidemic; 425 million individuals reportedly had diabetes in 2017 (2). In patients with DM2, chronic hyperglycaemia leads to dysfunction of the kidneys, blood vessels, nerves and heart and the development of bone pathologies, such as osteoporosis, osteopenia, and osteoarthritis, that increase the risk of fractures $(1,3)$.

Patients with DM2 have increased bone mineral density (BMD) compared with individuals without diabetes (4); however, they have bone fragility, a higher incidence of fractures, changes in the bone microarchitecture and a decrease in bone mineral quality $(5,6)$. These bone tissue alterations appear to be due in part to an alteration in osteoblast function and mineral matrix formation.

Hyperglycaemia is the origin of impaired bone metabolism, bone formation imbalance and reduced osteoblast activity (7). For example, we previously observed that high glucose concentrations increase mineral matrix deposition but decrease the quality of formed crystals (8). In addition, chronic hyperglycaemia alters the specific activity of alkaline phosphatase (ALP) and increases the expression of interleukin (IL)-6, IL-8 and monocyte chemoattractant protein 1 mRNA (8). Hyperglycaemia can also stimulate increased production of reactive oxygen species (ROS), which inhibit osteoblastgenesis. Consequently, increased ROS production directly affects BMD, osteoblast metabolism and bone remodelling (9). Oxidative stress decreases runt-related transcription factor 2 (RUNX2), ALP and bone sialoprotein (BSP) expression in MC3T3-E1 osteoblasts (10). Moreover, in rabbit osteoblasts, 
elevated ROS inhibits the nuclear translocation of RUNX2 and osteoblastic differentiation, but increases the nuclear translocation of nuclear factor $\kappa$-light-chain-enhancer of activated $\mathrm{B}$ cells $(\mathrm{NF}-\kappa \mathrm{B})$, associated with pro-inflammatory processes and bone resorption (11).

Docosahexaenoic acid (DHA) is an omega-3 long-chain polyunsaturated fatty acid with antioxidant effects; it is speculated to reduce mitochondrial depolarisation and increase antioxidant mechanisms $(12,13)$. DHA also exhibits anti-inflammatory effects through a cross-talk mechanism between the nuclear factor erythroid 2-related factor-2 (NRF2)/haem oxygenase-1 (HO-1) antioxidant pathway and the inflammatory $\mathrm{I} \kappa \mathrm{B}$ kinase $(\mathrm{IKK}) / \mathrm{NF}-\kappa \mathrm{B}$ pathway (14). In this regard, it has been suggested that DHA ameliorates rheumatoid arthritis by inhibiting IL- $1 \beta$ and IL- 6 expression (15). Besides, the DHA blood concentration is positively associated with BMD in healthy men (16). A DHA-rich diet increases bone density and the trabecular number, decreases trabecular separation, and contributes to peak bone mass in mice and rats $(17,18)$. Moreover, increased dietary intake of DHA aids in bone formation, inducing and preserving bone mass due to an increase in mesenchymal stem cells (19) and their maturation to osteoblasts (20). DHA diminishes the number of bone-resorptive cells by suppressing the proliferation and differentiation of bone marrow-derived macrophages and by enhancing the apoptosis of mature osteoclasts (21). In vitro studies have shown that DHA treatment in MC3T3-E1 osteoblast-like cells from mice increases mineral nodule formation without altering their distribution (22). Based on the beneficial effects of DHA on bone tissue, and considering its anti-inflammatory and antioxidant mechanisms, we decided to investigate whether DHA could counteract the alterations caused by a high glucose concentration on the biomineralization process, mineral quality and ROS production in a human osteoblast cell line.

\section{Materials and methods}

Cell culture. The human osteoblast cell line hFOB 1.19 (American Type Culture Collection; CRL-11372) was maintained in Dulbecco's modified Eagle's medium (DMEM; Invitrogen; Thermo Fisher Scientific, Inc.). It was confirmed that the cell culture was mycoplasma free by using a DNA staining method (bisBenzimide H 33258; Sigma-Aldrich; Merck KGaA). Osteoblasts were cultured with a glucose concentration of $5.5 \mathrm{mM}$. All media were supplemented with $10 \%$ foetal bovine serum (FBS; Mediatech, Probiotek SA de $\mathrm{CV}$, Mexico), $100 \mathrm{IU} / \mathrm{ml}$ penicillin and $100 \mu \mathrm{g} / \mathrm{ml}$ streptomycin (Sigma-Aldrich; Merck KGaA). Incubations were performed at $37^{\circ} \mathrm{C}$ in $5 \% \mathrm{CO}_{2}$ in humidified air. Cells between the third and fourth passages were used for all experiments.

Culture conditions and DHA treatments. A stock solution of DHA (cis-4,7,10,13,16,19-Docosahexaenoic acid; $\mathrm{C}_{22} \mathrm{H}_{32} \mathrm{O}_{2}$; CAS no. 6217-54-5; Sigma-Aldrich; Merck KGaA) was prepared in dimethyl sulfoxide (DMSO; Sigma-Aldrich; Merck $\mathrm{KGaA}$ ) and diluted in complete culture medium. The final concentration of DMSO was $0.01 \%$, which did not provoke any toxic effects (23). This same DMSO concentration was used as the vehicle control.
To analyse the effects of DHA, two concentrations were used (10 and $20 \mu \mathrm{M})$, which have been reported to induce osteoblastic differentiation and increase mineralisation, and they have no adverse impact on osteoblast proliferation (24). DHA was added every $48 \mathrm{~h}$ when the medium was changed, and it was prepared fresh to avoid its oxidation.

Cell differentiation and matrix mineralisation were induced with osteogenic medium [OM; $2.5 \mathrm{mM}$ ascorbic acid (Sigma-Aldrich; Merck KGaA) and $10 \mathrm{mM} \beta$-glycerophosphate (Sigma-Aldrich; Merck KGaA)] supplemented with 10\% FBS. The cells were cultured in low-glucose DMEM (DMEM-LG) with $5.5 \mathrm{mM}$ glucose, which is equivalent to physiological glucose levels (99 mg/dl in blood), normal glucose (NG). In addition, DMEM containing $24 \mathrm{mM}$ glucose (Invitrogen; Thermo Fisher Scientific, Inc.), high glucose (HG), was used. This concentration is equivalent to $432 \mathrm{mg} / \mathrm{dl}$ glucose in the blood and represents chronic hyperglycaemia. Alterations in osteoblast mineralisation have been observed at this glucose concentration $(8,9)$. Finally, DMEM-LG $(5.5 \mathrm{mM}$ glucose) supplemented with $18.5 \mathrm{mM}$ mannitol (Man; Sigma-Aldrich; Merck KGaA) was used as an osmotic control. In each experiment, the cells were distributed among the following experimental groups: i) $\mathrm{NG}$; ii) $\mathrm{NG}+10 \mu \mathrm{M}$ DHA; iii) $\mathrm{NG}+$ $20 \mu \mathrm{M}$ DHA; iv) HG; v) $\mathrm{HG}+10 \mu \mathrm{M}$ DHA; vi) $\mathrm{HG}+20 \mu \mathrm{M}$ DHA; and vii) $\mathrm{NG}+18.5 \mathrm{mM}$ Man.

Mineralisation analysis. hFOB 1.19 cells were seeded at a density of $8 \times 10^{4}$ cells $/ \mathrm{cm}^{2}$ in 12 -well cell culture plates (Corning, Inc.). When the cells reached semi-confluence, the conditioning medium was changed to OM containing glucose and DHA at the concentrations mentioned above and the cells were cultured for 7, 14 or 21 days.

The mineral matrix was fixed with $70 \%$ methanol at $4{ }^{\circ} \mathrm{C}$ for $1 \mathrm{~h}$, and mineral deposition was identified by using a saturated solution of 2\% Alizarin Red, pH 4.1 (Sigma-Aldrich; Merck $\mathrm{KGaA}$ ) for $2 \mathrm{~h}$ at room temperature. The stained mineral was observed with an inverted microscope (Zeiss AG). The dye was extracted with $10 \%$ acetic acid, and the supernatants were processed according to Gregory et al (25). Briefly, Alizarin Red-stained cell culture plates were stored at $-20^{\circ} \mathrm{C}$ for $1 \mathrm{~h}$. Then, $800 \mu 1$ 10\% (v/v) acetic acid solution was added and incubated for $30 \mathrm{~min}$ at room temperature under gentle agitation. All samples were collected with a cell scraper (Sigma-Aldrich; Merck KGaA) and then embedded in low-viscosity mineral oil. After polymerisation with heat for $10 \mathrm{~min}$ at $85^{\circ} \mathrm{C}$, the samples were placed on ice for $5 \mathrm{~min}$, followed by ultracentrifugation at $4^{\circ} \mathrm{C}, 25,545 \mathrm{x}$ g for $15 \mathrm{~min}$. Then, samples were transferred and incubated with $200 \mu 110 \%$ ammonium hydroxide/10\% acetic acid (v/v) for $30 \mathrm{~min}$ at room temperature to neutralise the acidification. Aliquots were read at $405 \mathrm{~nm}$ in a microplate reader (Biotek ELx 800; BioTek Instruments, Inc.).

Scanning electron microscopy (SEM). The morphologies and dimensions of the crystals formed in the experimental and control groups were examined with SEM at $20 \mathrm{kV}$. The powder of matrix samples was glued to a conductive adhesive supported on conventional copper cylinders and covered with gold particles to observe their morphology and surface roughness.

Briefly, cells were seeded in 24-well cell culture plates at a density of $2 \times 10^{5}$ cells/well. After $24 \mathrm{~h}$, the medium was 
changed to OM containing glucose and DHA at the concentrations mentioned above, and incubation was continued for 21 days. Then, samples were fixed with $2 \%$ glutaraldehyde for $24 \mathrm{~h}$ at $4^{\circ} \mathrm{C}$, and subsequently washed with wash buffer $[0.48 \mathrm{~g}$ sodium phosphate monobasic and $2.84 \mathrm{~g}$ sodium phosphate dibasic in $100 \mathrm{ml}$ double-distilled water $\left.\left(\mathrm{ddH}_{2} \mathrm{O}\right)\right]$. Finally, cells were dehydrated with a graded series of alcohol from 25 to $100 \%$ and allowed to dry completely. Samples were covered with colloidal gold before observation with SEM. The crystals formed were observed under the microscope (Leica-Cambridge 440; Leica Microsystems, Ltd.). The SEM analysis was performed at $20 \mathrm{kV}$ for $300 \mathrm{sec}$, and representative micrographs of each treatment were taken.

\section{Protein expression in the mineralised matrix}

Staining. The expression of collagen type 1 (Col1) was determined by staining with Picro-Sirius Red, according to Tullberg-Reinert and Jundt (26). Briefly, cells were cultured in 24-well plates at a density of $8 \times 10^{4}$ cells $/ \mathrm{ml}$ until semi-confluence was reached. Cells were distributed among experimental groups as described above and cultured in OM for 7, 14 or 21 days. As a negative control for mineralization, osteoblasts were cultured in DMEM-LG without mineralizing medium. The mineral matrix was fixed with Bouin's solution (saturated picric acid, formaldehyde, and acetic acid at a ratio of 15:5:1) for $1 \mathrm{~h}$ at room temperature. The matrices were stained with a 1:1 solution of Direct Red 80 (Sigma-Aldrich; Merck KGaA) in a saturated solution of picric acid for $1 \mathrm{~h}$ at room temperature. The staining solution was removed, and the cells were washed three times with $0.1 \%$ acetic acid. Micrographs of each of the treatments were taken with a Zeiss inverted microscope (magnification, x10).

In-cell western assay. An in-cell western assay was performed to determine the expression of osteocalcin (OCN). hFOB 1.19 cells were seeded at a density of $2 \times 10^{4}$ cells/well in 96-well plates until semi-confluence was reached. The cells were distributed among experimental groups as described above and cultured in OM for 7, 14 or 21 days. As a negative control for mineralization, osteoblasts were cultured in DMEM-LG without mineralizing medium. The mineral matrix was fixed with $70 \%$ ethanol at room temperature until complete evaporation. Non-specific binding was blocked with $5 \%$ bovine serum albumin (BSA; cat. no. BSA-BAF-100; Cientifica Senna S.A. de C.V.) at room temperature for $90 \mathrm{~min}$.

The matrices were first incubated with a goat anti-OCN antibody (1:100; cat. no. sc-18319; Santa Cruz Biotechnology, Inc.) diluted in Tris-buffered saline with $0.1 \%$ Tween-20 (TBST; pH 7.6) overnight at $4^{\circ} \mathrm{C}$. The matrices were washed three times for $10 \mathrm{~min}$ with TBST, and then incubated with the IRDye 680RD anti-goat IgG secondary antibody (1:500; cat. no. P/N: 926-68074 LI-COR Biosciences) for $1 \mathrm{~h}$ at room temperature. Incubation with only the secondary antibody was used as a negative control. The binding was visualised with an infrared scanner (Odyssey CLx; LI-COR Biosciences). The mean fluorescence intensity was quantified with Image J 1.50i software (National Institutes of Health).

Western blotting. For the analysis of bone sialoprotein type II (BSP-II) expression, cells were seeded in a $25 \mathrm{~cm}^{2}$ culture flask at $4 \times 10^{5}$ and cultured until they reached semi-confluence. The cells were distributed among the experimental groups as described above and cultured in OM for 7, 14 or 21 days. Cells and extracellular matrix in the culture flask were lysed with $3 \mathrm{ml}$ lysis buffer (20 mM HEPES, 1 mM EGTA, $210 \mathrm{mM}$ Mannitol and $70 \mathrm{mM}$ sucrose, $\mathrm{pH}$ 7.2). The insoluble fraction was separated by centrifugation at $4^{\circ} \mathrm{C}$ and $1,618 \mathrm{x} \mathrm{g}$, and the soluble proteins were quantified by using the Bradford method (27). A total of $2 \mu \mathrm{g}$ soluble protein of the mineral matrix was loaded per lane onto $10 \%$ acrylamide gels and subjected to separation via sodium dodecyl sulphate-polyacrylamide gel electrophoresis. The separated protein was transferred to a nitrocellulose membrane. Unspecific binding was blocked with fat free milk at $6 \%$ for $1 \mathrm{~h}$ at room temperature. The membrane was incubated with rabbit anti-BSP-II (1:1,000; cat. no. sc-73634; Santa Cruz Biotechnology, Inc.) overnight at $4^{\circ} \mathrm{C}$, followed by incubation with the IRDye $800 \mathrm{CW}$ anti-rabbit IgG secondary antibody (1:1,000; cat. no. P/N: 926-32211 LI-COR Biosciences) for $1 \mathrm{~h}$ at room temperature. The binding was visualised with an infrared scanner (Odyssey CLx; LI-COR Biosciences). BSP-II was detected at an approximate weight of $80 \mathrm{kDa}$, and protein expression was semi-quantified by image densitometry in ImageJ 1.50 i software. Ponceau red staining of an $80 \mathrm{kDa}$ band was used as a loading control (28).

ALP specific activity. hFOB 1.19 cells were plated at $1.5 \times 10^{5}$ cells/well in 6 -well plates with OM. The cells were distributed among the experimental groups as described above and cultured for 7 or 14 days as ALP is an early mineralisation marker (29). After the incubation period, the cell monolayer was lysed with $10 \mathrm{mM}$ Tris- $\mathrm{HCl}$ and $0.1 \%$ Triton $\mathrm{X}-100, \mathrm{pH} 7.4$. The proteins were separated using ultra-centrifugation filters with a molecular weight cut-off of $100 \mathrm{kDa}$ (Amicon Ultra; MilliporeSigma). The enzymatic activity was evaluated in the $>100 \mathrm{kDa}$ protein fraction as human bone-specific ALP has an approximate weight of $140 \mathrm{kDa}(30)$. The total protein was quantified according to the modified method of Lowry (31). The enzymatic activity was evaluated by using $24 \mu \mathrm{g} / \mathrm{ml}$ total protein with the QuantiChrom Alkaline Phosphatase Assay Kit (DALP-250; cat. no. 75877-954 BioAssay Systems), using $10 \mathrm{mM}$ p-nitrophenyl phosphate (pNPP) as a substrate in a solution with $5 \mathrm{mM}$ magnesium acetate at $\mathrm{pH}$ 10.5. The samples were read on a plate reader at $405 \mathrm{~nm}$ for three periods of 4 min each.

Fourier-transform infrared spectroscopy (FTIR). The mineralised matrices were characterised by FTIR (FT-IR Spectrum One; PerkinElmer, Inc.). The FTIR spectrum was taken in the mid-IR region of $400-4,000 \mathrm{~cm}^{-1}$. The sample was placed directly on the quartz surface, and the spectrum was recorded in transmittance mode. The laser output power was $\sim 108 \mathrm{~mW}$, and the system's spectral resolution was set to $4.0 \mathrm{~cm}^{-1}$. For each sample, three spectra were collected with a distance of $10 \mu \mathrm{m}$ between them, using 40 scans, totalling 54 spectra. The calculation of peak areas was performed with FTIR Toolbox 3.5 (Operant LLC). The peak areas in the intervals of 900-1,200 $\mathrm{cm}^{-1}\left(v_{1}, v_{3} \mathrm{PO}_{4}{ }^{3-}\right.$ phosphate, inorganic content), $1,600-1,700 \mathrm{~cm}^{-1}$ (amide I), 1,250-1,370 $\mathrm{cm}^{-1}$ (amide III) and $850-890 \mathrm{~cm}^{-1}\left(v_{2} \mathrm{CO}_{3}{ }^{2-}\right)$ as reported in the literature were analysed to characterise changes in the bone mineral and organic matrix (32). 
To this end, $8 \times 10^{4}$ cells were seeded in 12-well cell culture plates until they reached semi-confluence. Cells were distributed among the experimental groups as described above and cultured in OM for 21 days. The mineral matrix was fixed with $70 \%$ ethanol at room temperature until complete evaporation. The samples were sprayed and oriented in an infrared spectrometer (FT-IR Spectrum One; PerkinElmer, Inc.), with 40 scans per sample. The spectra were obtained as percent transmission and displacement in $\mathrm{cm}^{-1}$. All histograms obtained were converted to absorbance, and the double derivative was calculated and normalised to the baseline with the essential software FTIR Toolbox 3.5 (Operant LLC). An integration analysis of the characteristic displacement of each functional group was performed. The substitution of carbonates was determined when calculating the ratio of the bands $v_{2} \mathrm{CO}_{3}{ }^{2-} / v_{1}, v_{3} \mathrm{PO}_{4}{ }^{3}$ (850-890 $\left.\mathrm{cm}^{-1} / 900-1,200 \mathrm{~cm}^{-1}\right)$, and the relative mineralisation of organic matrix was determined when calculating the radius between the bands of amide I and III, which is characteristic of Col1, with phosphate bands $\left(900-1,200 \mathrm{~cm}^{-1} / 1,250-1,370 \mathrm{~cm}^{-1}\right.$ and $\left.900-1,200 \mathrm{~cm}^{-1} / 1,600-1,700 \mathrm{~cm}^{-1}\right)$.

Receptor activator of nuclear factor $\kappa$-B ligand (RANK-L) detection. hFOB 1.19 cells were cultured at $1 \times 10^{5}$ cells/well in a 12 -well plate and incubated at $37^{\circ} \mathrm{C}$ in $5 \% \mathrm{CO}_{2}$ in humidified air with DMEM without phenol red for $24 \mathrm{~h}$. The cells were distributed among the experimental groups as described above. Each condition was replicated three times. The RANK-L content of the supernatants was assessed with a RANK-L (total), soluble (human) ELISA kit (cat. no. ALX-850-019-KI01; Enzo Life Sciences, Inc.) according to the technical specifications of the manufacturer.

ROS detection. ROS were detected by using the fluorescent probe 2',7'-Dichlorofluorescein diacetate ( $\mathrm{H}_{2}$ DCFDA), which is a ROS-sensitive dye. hFOB 1.19 cells were cultured at $1.5 \times 10^{5}$ cells/well in a 12 -well culture plate. As a negative control, one of the wells was pre-treated with $30 \mu \mathrm{M}$ Trolox (an antioxidant; (士)-6-Hydroxy-2,5,7,8-tetramethylchromane-2-carboxylic acid; Sigma-Aldrich; Merck KGaA; cat. no. 238813) for $1 \mathrm{~h}$ at $37^{\circ} \mathrm{C}$. Subsequently, the cells were treated with DMEM without phenol red with 5.5 or $24 \mathrm{mM}$ glucose, with or without 10 or $20 \mu \mathrm{M} \mathrm{DHA}$, and incubated for $24 \mathrm{~h}$ at $37^{\circ} \mathrm{C}$. Then, $30 \mathrm{~min}$ before the end of the incubation, $30 \mathrm{mM}$ hydrogen peroxide $\left(\mathrm{H}_{2} \mathrm{O}_{2}\right)$ was added to the corresponding groups. After incubation for $24 \mathrm{~h}, \mathrm{H}_{2}$ DCFDA was added at a concentration of $15 \mu \mathrm{M}$ and incubated for $60 \mathrm{~min}$ at $37^{\circ} \mathrm{C}$. A flow cytometer (FACSCalibur; Becton, Dickinson and Company) with the BD Cell Quest Pro v.5.1.1 software (BD Biosciences) was used to capture and quantify the relative fluorescence intensity of 10,000 events. The obtained data were analysed by using FlowJo 7.6 (FlowJo LLC).

Reverse transcription-quantitative PCR (RT-qPCR) for $N R F 2$. hFOB 1.19 cells were seeded at a density of $1.5 \times 10^{5}$ cells $/ 25 \mathrm{~cm}^{2}$ flask. Subsequently, cells were cultured in phenol-red-free DMEM with 5.5 or $24 \mathrm{mM}$ glucose, with or without 10 or $20 \mu \mathrm{M}$ DHA. Cell cultures were maintained for a further $24 \mathrm{~h}$ or 7 days. Total RNA was extracted by using the TRIzol ${ }^{\circledR}$ (Invitrogen; Thermo Fisher Scientific,
Inc.) method (33). RT was performed by using a RevertAid RT Revert transcription kit (cat. no. K1691; Thermo Fisher Scientific, Inc.), with $2 \mu \mathrm{g}$ total RNA, $2 \mu \mathrm{g}$ Oligo (dT)18 (cat. no. SO131; Thermo Fisher Scientific, Inc.), 1 mM dNTP Mix (10 mM each) (cat. no. R0191; Thermo Fisher Scientific, Inc.), and 200 U RevertAid Reverse Transcriptase (cat. no. EP0441; Thermo Fisher Scientific, Inc.). RT was performed for $60 \mathrm{~min}$ at $42^{\circ} \mathrm{C}$, and terminated at $70^{\circ} \mathrm{C}$ for $10 \mathrm{~min}$. To standardize the alignment temperature, a number of cycles were run for each set of primers.

qPCR was performed with the Maxima SYBR Green/ROX qPCR Master Mix (cat. no. K0222; Thermo Fisher Scientific, Inc.) under the following conditions: One cycle of initial denaturation at $95^{\circ} \mathrm{C}$ for $1 \mathrm{~min} ; 30$ cycles of denaturation at $95^{\circ} \mathrm{C}$ for $30 \mathrm{sec}$, annealing at $58.5^{\circ} \mathrm{C}$ for $30 \mathrm{sec}$ for $\mathrm{NRF} 2$ or $60^{\circ} \mathrm{C}$ for $30 \mathrm{sec}$ for $18 \mathrm{~S}$ ribosomal 5 (18S Rib) (Accesolab S.A de C.V, México), and extension at $72^{\circ} \mathrm{C}$ for $1 \mathrm{~min}$; and one cycle of final extension at $72^{\circ} \mathrm{C}$ for $10 \mathrm{~min}$. The NRF2 primers (Accesolab S.A de C.V, México) used were as follows: NRF2 forward (F), 5'-GGCTACGTTTCAGTCACTTG-3' and reverse (R), 5'-AACTCAGGAATGGATAATAG-3' (Genbank, NM_001313904.1; product size 180 pb). The 18S Rib was used as a housekeeping gene, the primers were as follows: 18S Rib F, 5'-GGGAGCCTGAGAAACGGC-3' and R, 5'-GGGTCGGGAGTGGGTAATTT-3' (Genbank, NR_003286.2; product size $93 \mathrm{pb}$ ). Gene expression was calculated using the $2^{-\Delta \Delta \mathrm{Cq}}$ method (34).

Statistical analysis. The data are presented as the mean values \pm standard deviation (SD) that were calculated from at least three biological replicates with at least three internal repeats. The treatment groups were analysed by using one-way analysis of variance (ANOVA) followed by Tukey's post hoc test for multiple comparisons. All analyses were performed in GraphPad Prism 6 software (GraphPad Software, Inc.). $\mathrm{P}<0.05$ was considered to indicate a statistically significant difference.

\section{Results}

DHA restores the production of Coll, OCN and BSP-II altered by $H G$. To determine the effect of DHA on the organic components of the extracellular matrix under HG, an osteoblast cell line was cultured in OM with NG or HG, with or without DHA, and the production and distribution of mineral matrix proteins, Col1, OCN and BSP-II after 7, 14 and 21 days of culture were evaluated.

In osteoblasts cultured in NG, collagen scaffolds formed homogeneously, with linked small pores. Cells cultured in NG and treated with either DHA concentration showed no change in the production or distribution of Coll. HG increased the production and altered the distribution of the Coll scaffold; at day 21 of culture, the collagen scaffold did not show interconnectivity. Cells cultured in HG and treated with either DHA concentration showed improved distribution, homogeneity, and interconnectivity of the Coll scaffold compared with HG alone. The iso-osmotic control had a similar collagen scaffold to the NG control (Fig. 1A).

Osteoblasts cultured in NG presented increased OCN production in a time-dependent manner. Cells cultured in 
A $5.5 \mathrm{mM}$ Glucose+ $5.5 \mathrm{mM}$ Glucose+
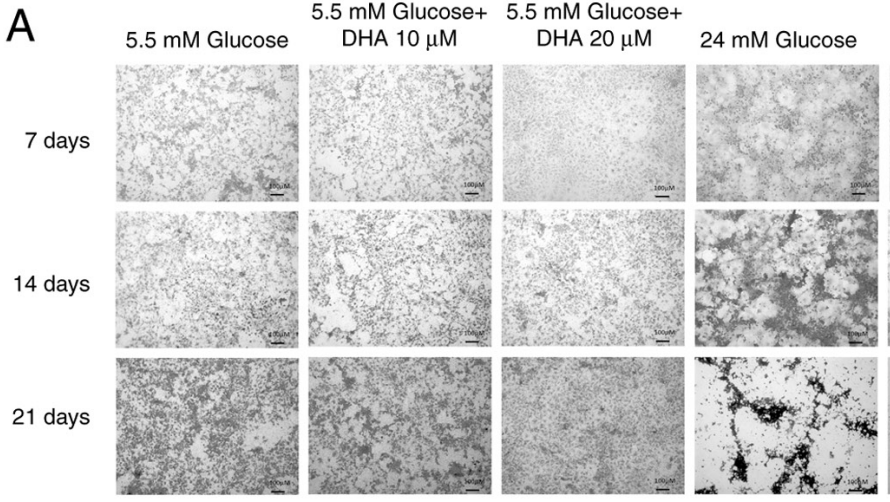

B
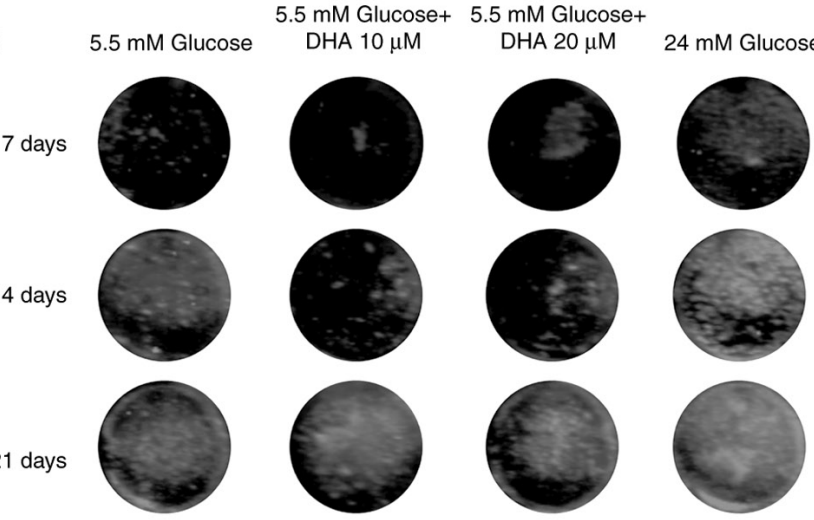
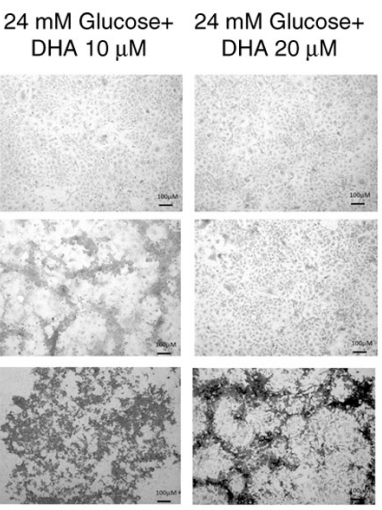

$18.5 \mathrm{mM}$ Mannitol

DMEM-LG

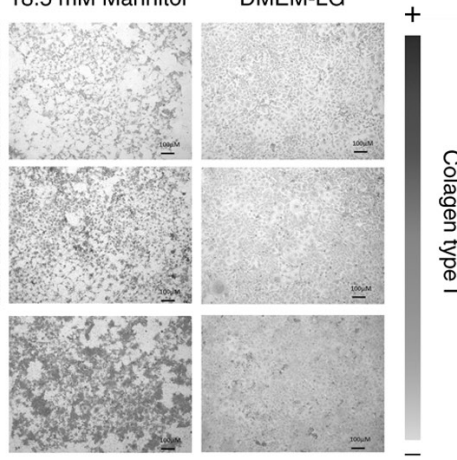

$24 \mathrm{mM}$ Glucose+ $24 \mathrm{mM} \mathrm{Glucose}+$ DHA $10 \mu \mathrm{M} \quad$ DHA $20 \mu \mathrm{M}$
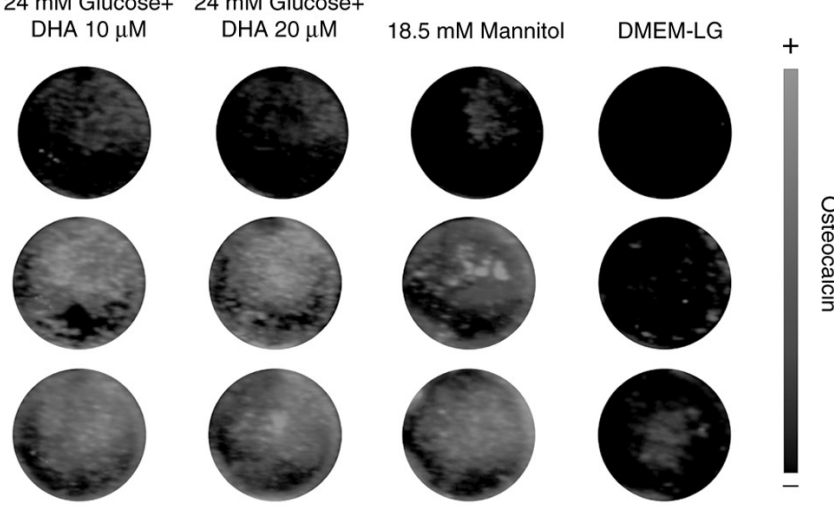

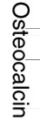
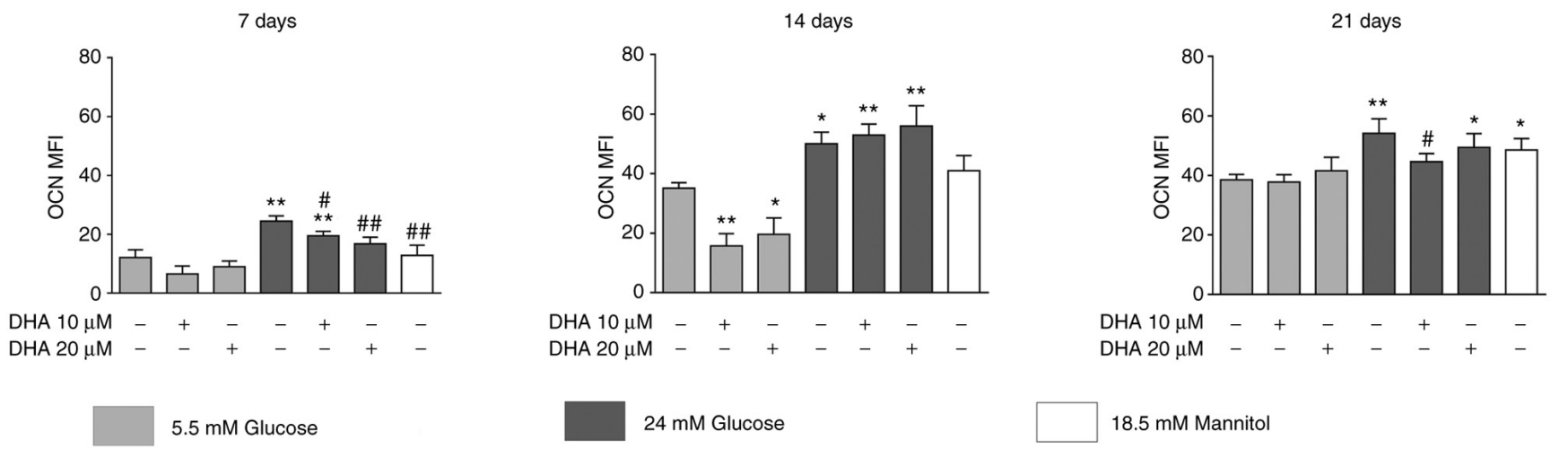

Figure 1. Effect of treatment with DHA at 5.5 or $24 \mathrm{mM}$ glucose concentrations on the production and distribution of Collagen type 1 and production of OCN. (A) Effect of DHA on the concentration and distribution of Collagen type 1 with different concentrations of glucose (magnification, $\mathrm{x} 10$; scale bar, $100 \mu \mathrm{m}$ ). (B) Effect of DHA on the production of OCN with different concentrations of glucose. Representative images. The bar graphs represent the mean \pm SD of the mean fluorescence intensity of three independent experiments. ${ }^{*} \mathrm{P}<0.05$ and ${ }^{* *} \mathrm{P}<0.01$ vs. control $\left(5.5 \mathrm{mM}\right.$ glucose); ${ }^{*} \mathrm{P}<0.05$ and ${ }^{\# \#} \mathrm{P}<0.01 \mathrm{vs}$. $24 \mathrm{mM}$ glucose. DHA, docosahexaenoic acid; OCN, osteocalcin; DMEM, Dulbecco's modified Eagle's medium; LG, low glucose; MFI, median fluorescence intensity.

NG and treated with either DHA concentration showed significantly decreased OCN production at day 14 compared with NG alone. Cells cultured in HG had increased OCN expression. Cells cultured in $\mathrm{HG}$ and treated with either DHA concentration presented significantly increased OCN expression at days 7 and 14 compared with NG. At day 21 of culture, cells cultured in HG and treated with $20 \mu \mathrm{M}$ DHA showed significantly increased OCN expression compared with NG, but $10 \mu \mathrm{M}$ DHA induced similar expression of OCN compared with NG. The iso-osmotic control behaved similarly to the NG control regarding OCN production (Fig. 1B).

Cells cultured in NG and treated with $20 \mu \mathrm{M}$ DHA showed significantly increased BSP-II production at day 7 compared with cells cultured in NG alone. Osteoblasts cultured in HG presented significantly decreased BSP-II expression compared with cells cultured in NG at days 7, 14 and 21. Cells cultured in HG and treated with either DHA concentration showed BSP-II protein expression that was like that of the NG control at days 7 and 14. At day 21 of culture, these treatments increased BSP-II protein expression compared with HG alone, but to an equivalent level as NG. The iso-osmotic control behaved similarly to the NG control (Fig. 2A and B).

DHA attenuates the increase in ALP specific activity in the presence of HG. Cells cultured in NG with and without DHA treatment showed similar levels of ALP specific activity at days 7 and 14. Cells cultured in HG demonstrated a significant increase in ALP activity compared with cells cultured in 

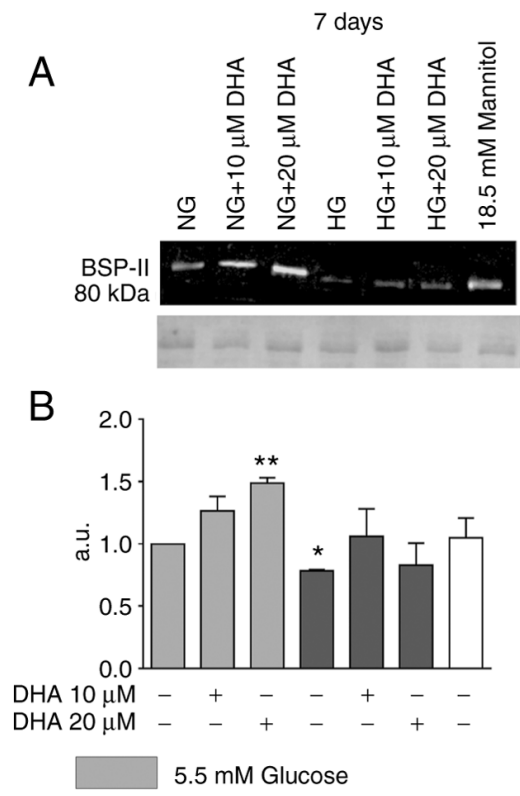
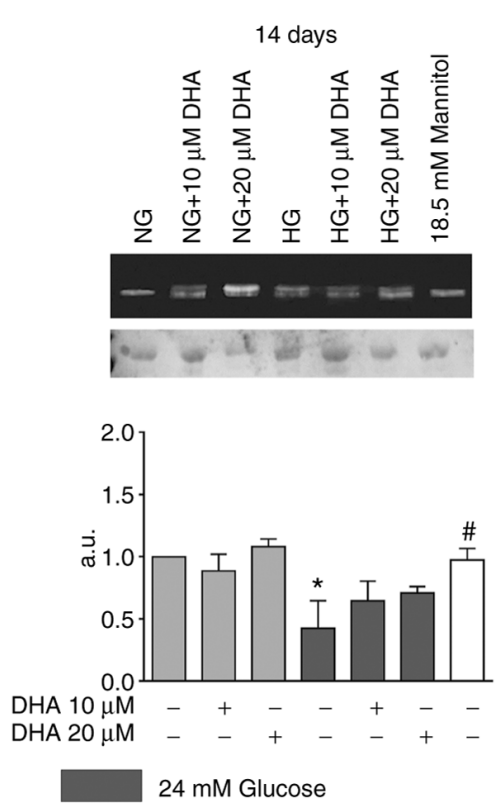
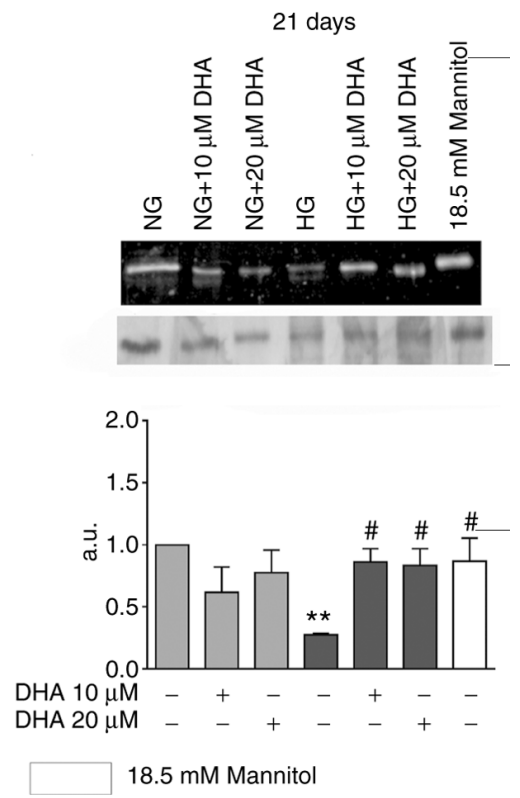

Figure 2. Effect of DHA with 5.5 or $24 \mathrm{mM}$ glucose concentrations on the production of BSP-II. Immunoblot of BSP-II detected by infrared. (A) Representative images of the results of the expression of BSP-II obtained by western blotting. (B) Densitometry results obtained by normalization of BSP-II expression to the control (5.5 mM of glucose) of three independent experiments expressed in a.u. The graphs represent the mean $\pm \mathrm{SD}$. ${ }^{*} \mathrm{P}<0.05$ and ${ }^{* *} \mathrm{P}<0.01 \mathrm{vs}$. control (5.5 $\mathrm{mM}$ glucose); ${ }^{\text {P }}<0.05$ vs. HG group ( $24 \mathrm{mM}$ glucose). DHA, docosahexaenoic acid; BSP-II, bone sialoprotein type-II; a.u., arbitrary units; NG, normal glucose (5.5 mM glucose); $\mathrm{HG}$, high glucose (24 mM glucose).

NG alone at days 7 and 14. Osteoblasts cultured in HG and treated with either DNA concentration exhibited significantly decreased ALP activity compared with HG alone; the levels were similar to those of cells cultured in NG at days 7 and 14 . The iso-osmotic control behaved similarly to the NG control (Fig. 3).

DHA decreases elevated mineral formation and calcium in the presence of $H G$. Next, the formation and mineralisation of calcium nodules was evaluated. Osteoblasts cultured in NG and treated with $10 \mu \mathrm{M}$ DHA demonstrated a similar number and shape of mineralised nodules as the NG group. Cells cultured in NG and treated with $20 \mu \mathrm{M}$ DHA showed fewer mineralised nodules (Fig. 4A) and lower calcium concentration (Fig. 4B) at days 14 and 21 but increased mineral crystal size (Fig. 4C) at 21 days. The cells cultured in NG and treated with either DHA concentration showed bone mineral crystals with a nanoscale, needle-like shape (Fig. 4C). The iso-osmotic control behaved like the NG control (Fig. 4A-C).

Osteoblasts cultured in $\mathrm{HG}$ had more mineralised nodules (Fig. 4A) and increased calcium concentration (Fig. 4B) at days 14 and 21. As shown by SEM, the mineral crystals formed were amorphous and disorganised in the extracellular matrix (Fig. 4C). Cells cultured in HG and treated with either DHA concentration showed fewer mineralised nodules (Fig. 4A) and lower calcium concentration (Fig. 4B) at day 21 compared with cells cultured in $\mathrm{HG}$ alone and similar numbers to the NG control (Fig. 4A and B). The mineral crystals formed for cultures in HG with DHA treatment were amorphous and similar to the cells cultured in $\mathrm{HG}$ alone but were more organised in mineralised nodules (Fig. 4C). The iso-osmotic control showed similar numbers and sizes of mineralised nodules as the NG control (Fig. 4A-C).

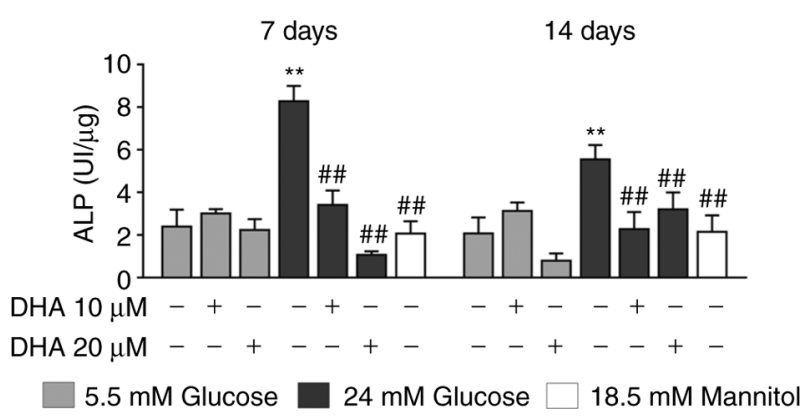

Figure 3. Effect of DHA with 5.5 or $24 \mathrm{mM}$ glucose concentrations on the specific activity of ALP. Results of the enzymatic activity of ALP expressed in IU $/ \mu$ g of protein. The graphs represent the mean $\pm \mathrm{SD} .{ }^{* *} \mathrm{P}<0.01$ vs. control (5.5 mM glucose); ${ }^{\# \#} \mathrm{P}<0.01$ vs. $24 \mathrm{mM}$ glucose. DHA, docosahexaenoic acid; ALP, alkaline phosphatase.

Treatment with DHA compensates for carbonate substitution altered by $H G$. Due to the differences in collagen distribution, calcium concentration and the shape of mineral crystals among treatments, FTIR was used to measure the quality and chemical composition of the minerals formed. The spectra obtained for cells cultured in NG or HG with and without DHA treatment are shown in Fig. 5. All samples showed a very similar FTIR spectrum in terms of the peak positions and shapes. All FTIR spectra showed absorption bands characteristic of minerals, the peak phosphate group $\left(\mathrm{v}_{1}, \mathrm{v}_{3} \mathrm{PO}_{4}{ }^{3-}\right)$ and the carbonate band $\left(\mathrm{v}_{2} \mathrm{CO}_{3}{ }^{2-}\right)$ in the $900-1,0212 \mathrm{~cm}^{-1}$ range, and $854-892 \mathrm{~cm}^{-1}$ range, respectively (Table I).

The absorption bands characteristic of the organic matrix were observed as spectral peaks within the amide I and III groups from 1,620-1,635 $\mathrm{cm}^{-1}$ and from 1,277-1,280 $\mathrm{cm}^{-1}$, respectively (Table I). Table II shows the mineral/matrix ratio $\left(\mathrm{v}_{1}, \mathrm{v}_{3} \mathrm{PO}_{4}{ }^{3-}\right.$ /amide $\mathrm{I} ; \mathrm{v}_{1}, \mathrm{v}_{3} \mathrm{PO}_{4}{ }^{3-}$ /amide III) and the 
A
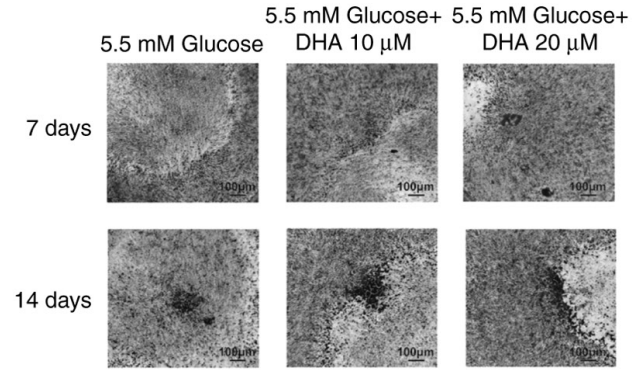

21 days
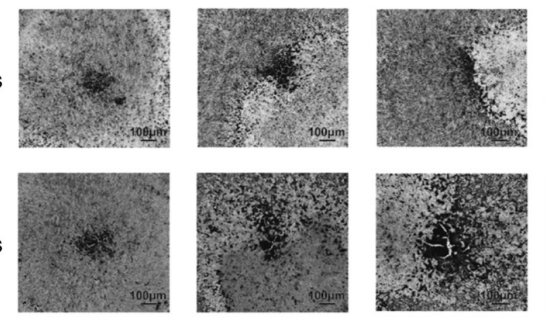

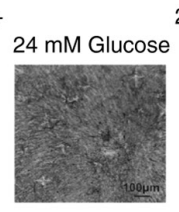

$24 \mathrm{mM}$ Glucose+ $24 \mathrm{mM}$ Glucose+
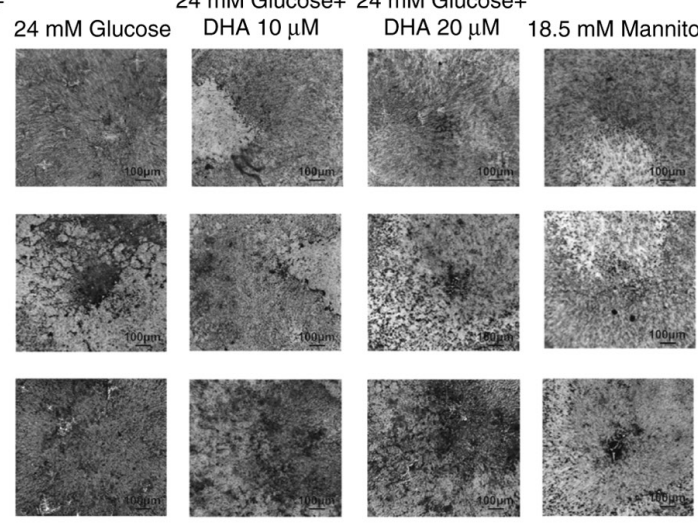

B
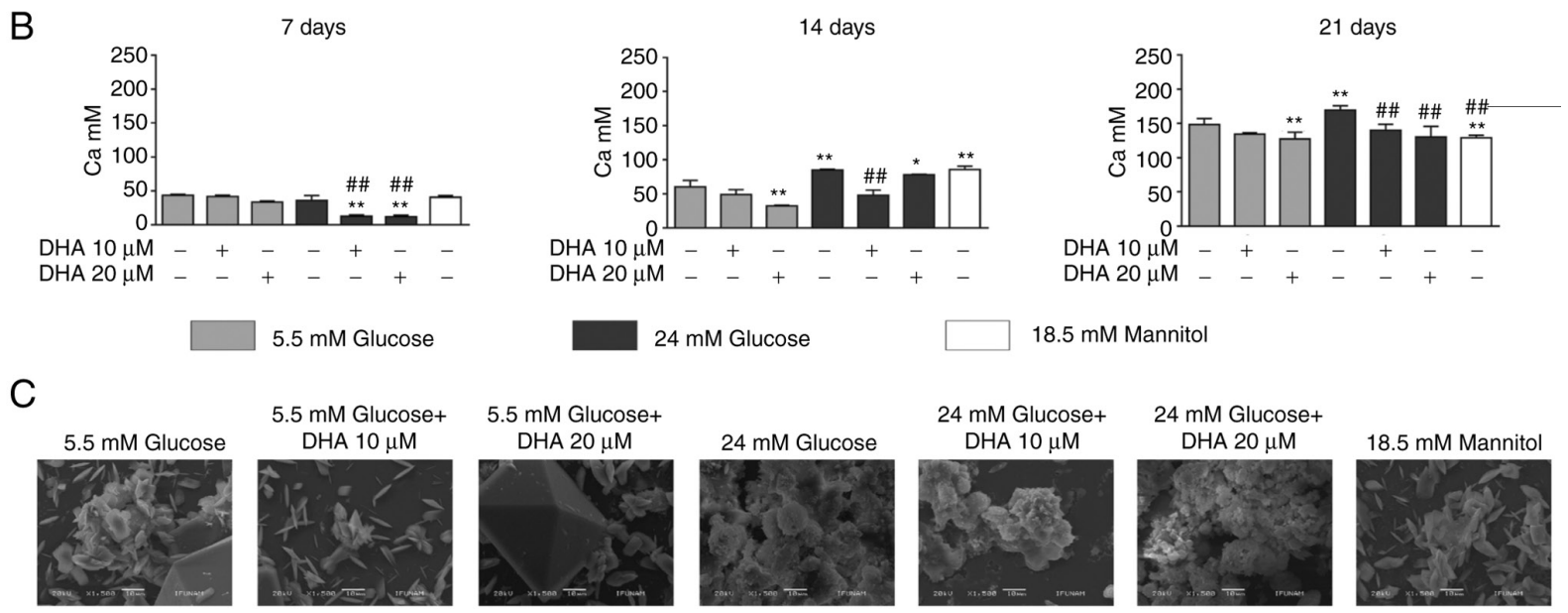

Figure 4. Effect of DHA with 5.5 or $24 \mathrm{mM}$ glucose concentrations on biomineralization. (A) Effect of DHA on the mineral matrix formation under $5.5 \mathrm{mM}$ or $24 \mathrm{mM}$ glucose. Representative microphotographs are shown. (B) Extraction of the dye was performed to quantify the amount of calcium (Ca) in the culture (scale bars, $100 \mu \mathrm{m}$ ). (C) Effect of DHA on crystal morphology formed by osteoblasts under conditions of $5.5 \mathrm{mM}$ or $24 \mathrm{mM}$ glucose by scanning electron microscopy (magnification, $\mathrm{x} 250$ ). The graphs represent the mean \pm SD. ${ }^{*} \mathrm{P}<0.05$ and ${ }^{* *} \mathrm{P}<0.01$ vs. control (5.5 mM glucose); ${ }^{\# \#} \mathrm{P}<0.01$ vs. $24 \mathrm{mM}$ glucose. DHA, docosahexaenoic acid.

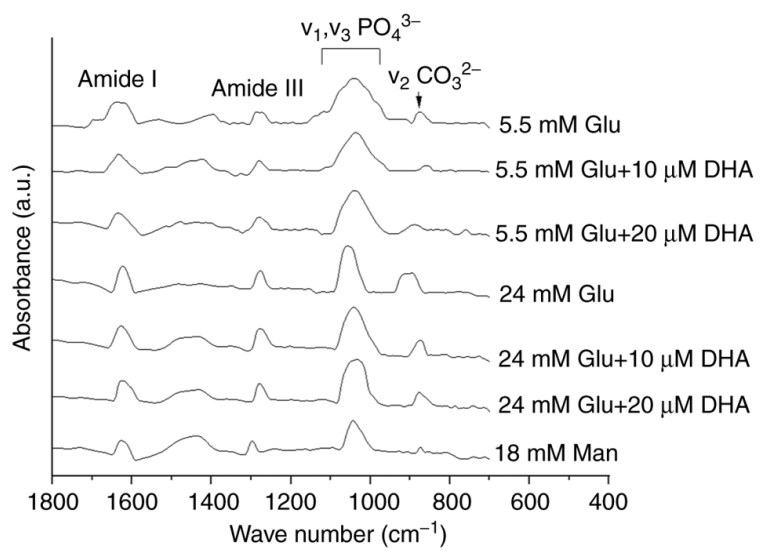

Figure 5. Effect of DHA with 5.5 or $24 \mathrm{mM}$ glucose concentrations on relative mineralization and carbonate substitution. Representative spectra obtained by Fourier-transform infrared spectroscopy of the mineral matrix. Bands of amide I in 1,599-1,701 $\mathrm{cm}^{-1}$, amide III in $1,250-1,371 \mathrm{~cm}^{-1}$, phosphate group $\left(\mathrm{v}_{1}, \mathrm{v}_{3} \mathrm{PO}_{4}{ }^{3-}\right)$ in $900-1,212 \mathrm{~cm}^{-1}$ and carbonate $\left(\mathrm{v}_{2} \mathrm{CO}_{3}{ }^{2-}\right)$ in $854-892 \mathrm{~cm}^{-1}$ are shown. DHA, docosahexaenoic acid.

carbonate/phosphate ratio $\left(\mathrm{v}_{2} \mathrm{CO}_{3}{ }^{2-} / \mathrm{v}_{1}, \mathrm{v}_{3} \mathrm{PO}_{4}^{3-}\right)$ and their comparison among the groups. The mineral/matrix and carbonate/phosphate ratios in the cells cultured in NG alone were very similar to those of the cells cultured in NG and treated with DHA (Table II). For cells cultured in HG, the mineral/matrix ratio was lower than cells cultured in NG and the carbonate/phosphate ratio was higher than cells cultured in NG (Table II). Osteoblasts cultured in HG and treated with either DHA concentration showed a mineral/matrix ratio like that of cells cultured in HG alone. Still, the carbonate/phosphate ratio was more similar to the cells cultured in NG alone rather than HG alone (Table II). The iso-osmotic group did not show notable differences in the mineral/matrix and carbonate/phosphate ratios compared with the NG control (Table II).

Treatment with DHA reduces ROS overproduction induced by $H G$. ROS are critical mediators in the pathogenesis of bone pathologies (35). To determine whether the antioxidant properties of DHA underlie its ability to counteract the bone mineralisation alterations caused by HG, ROS production was measured. Osteoblasts cultured in NG and treated with DHA or Trolox showed similar ROS production compared with cells cultured in NG alone. Osteoblasts cultured in HG alone showed significantly increased ROS production compared with cells cultured in NG alone. However, cells cultured in HG and treated with either DHA concentration showed significantly 
Table I. Fourier-transform infrared spectroscopy absorption bands of mineral matrix.

\begin{tabular}{|c|c|c|c|c|c|c|c|}
\hline \multirow[b]{2}{*}{ Assignment } & \multicolumn{7}{|c|}{ Peak position $\left(\mathrm{cm}^{-1}\right)$} \\
\hline & NG & $\begin{array}{c}\mathrm{NG}+10 \mu \mathrm{M} \\
\text { DHA }\end{array}$ & $\begin{array}{c}\mathrm{NG}+20 \mu \mathrm{M} \\
\text { DHA }\end{array}$ & HG & $\begin{array}{c}\mathrm{HG}+10 \mu \mathrm{M} \\
\text { DHA }\end{array}$ & $\begin{array}{c}\mathrm{HG}+20 \mu \mathrm{M} \\
\text { DHA }\end{array}$ & $\begin{array}{l}18.5 \mathrm{mM} \\
\text { mannitol }\end{array}$ \\
\hline Amide I $\left(1,599-1,701 \mathrm{~cm}^{-1}\right)$ & 1,630 & 1,633 & 1,635 & 1,623 & 1,627 & 1,620 & 1,624 \\
\hline Amide III $\left(1,250-1,371 \mathrm{~cm}^{-1}\right)$ & 1,278 & 1,277 & 1,278 & 1,280 & 1,279 & 1,278 & 1,297 \\
\hline$v_{1}, v_{3} \mathrm{PO}_{4}^{3-}\left(900-1,212 \mathrm{~cm}^{-1}\right)$ & 1,040 & 1,037 & 1,038 & 1,054 & 1,044 & 1,038 & 1,042 \\
\hline$v_{2} \mathrm{CO}_{3}^{2-}\left(854-892 \mathrm{~cm}^{-1}\right)$ & 875 & 860 & 887 & 894 & 874 & 876 & 875 \\
\hline
\end{tabular}

DHA, docosahexaenoic acid; NG, normal glucose; HG, high glucose.

Table II. Ratio of mineral/matrix and carbonate/phosphate.

\begin{tabular}{|c|c|c|c|c|c|c|c|}
\hline Ratio & NG & $\begin{array}{c}\mathrm{NG}+10 \mu \mathrm{M} \\
\mathrm{DHA}\end{array}$ & $\begin{array}{c}\mathrm{NG}+20 \mu \mathrm{M} \\
\mathrm{DHA}\end{array}$ & HG & $\begin{array}{c}\mathrm{HG}+10 \mu \mathrm{M} \\
\mathrm{DHA}\end{array}$ & $\begin{array}{c}\mathrm{HG}+20 \mu \mathrm{M} \\
\mathrm{DHA}\end{array}$ & $\begin{array}{l}18.5 \mathrm{mM} \\
\text { mannitol }\end{array}$ \\
\hline$v_{1}, v_{3} \mathrm{PO}_{4}^{3-} /$ Amide I & 2.33 & 1.96 & 1.66 & 1.50 & 1.52 & 1.87 & 1.71 \\
\hline$v_{1}, v_{3} \mathrm{PO}_{4}^{3-/ A m i d e ~ I I I ~}$ & 3.76 & 3.26 & 1.98 & 1.75 & 1.72 & 2.61 & 2.46 \\
\hline$v_{2} \mathrm{CO}_{3}^{2-} / v_{1}, v_{3} \mathrm{PO}_{4}^{3-}$ & 0.83 & 0.92 & 0.75 & 1.42 & 0.85 & 0.91 & 0.88 \\
\hline
\end{tabular}

DHA, docosahexaenoic acid; NG, normal glucose (5.5 mM of glucose); HG, high glucose (24 mM of glucose).

decreased ROS production compared with cells cultured in HG alone, similarly to the cells cultured in HG and treated with Trolox. The iso-osmotic control did not show changes in ROS production (Fig. 6A). The osteoblasts had the capacity to overproduce ROS, evidenced by the positive control group for ROS production $\left(30 \mathrm{mM} \mathrm{H}_{2} \mathrm{O}_{2}\right)$ and the antioxidant Trolox inhibited this overproduction (Fig. 6A).

Treatment of DHA increases NRF2 mRNA expression in $N G$ and $H G$. It was next speculated whether the inhibition of ROS production by DHA in the presence of HG could be due to the expression of NRF2, a master transcription factor related to cytoprotective genes against oxidative and chemical insults (36). Osteoblasts cultured in NG and treated with $20 \mu \mathrm{M}$ DHA showed significantly elevated NRF2 mRNA expression compared with cells cultured in NG alone for $24 \mathrm{~h}$ or 7 days. Osteoblasts cultured in HG alone showed significantly increased NRF2 mRNA expression compared with cells cultured in NG alone, but these levels were less than those observed in cells cultured in NG and treated with $20 \mu \mathrm{M}$ DHA for $24 \mathrm{~h}$ or 7 days.

Although osteoblasts cultured in $\mathrm{HG}$ and treated with $20 \mu \mathrm{M}$ DHA exhibited significantly increased NRF2 mRNA after $24 \mathrm{~h}$ compared with cells cultured in NG alone, these levels were similar to those of osteoblasts cultured in HG alone. However, after 7 days, osteoblasts cultured in $\mathrm{HG}$ and treated with $20 \mu \mathrm{M}$ DHA showed significantly more NRF2 mRNA than cells cultured in NG or HG alone. The level of NRF2 mRNA in the iso-osmotic control was similar to the NG group (Fig. 6B).

Treatment with DHA combined with HG partially decreases the extracellular concentration of RANK-L. To determine the indirect effect of DHA on osteoclastogenesis, RANK-L production was measured. Osteoblasts cultured in NG and treated with either DHA concentration expressed similar RANK-L levels to cells cultured in NG alone. Osteoblasts cultured in $\mathrm{HG}$ alone showed a significant increase in RANK-L compared with cells cultured in NG alone or with DHA treatment. Osteoblasts cultured in HG and treated with either DHA concentration exhibited significantly decreased RANK-L expression compared with cells treated with HG alone, but these levels were higher than those of cells cultured in NG alone or treated with DHA. The iso-osmotic control increased RANK-L production compared with NG, but the RANK-L level was lower than that seen in cells cultured in HG (Fig. 7).

\section{Discussion}

We previously observed that HG decreases the quality of hydroxyapatite (HAP) crystals in inorganic bone matrix (8), induces oxidative stress (9) and increases RANK-L production (8), and to the best of our knowledge the present study was the first to show the effect of DHA and the possible mechanisms by which it counteracts alterations caused by HG in mineralisation and oxidative stress of an osteoblast cell line. It was found that the addition of DHA in the presence of NG did not affect mineralisation of osteoblasts. This finding is contrary to the report by Coetzee et al (22), who demonstrated that DHA increases mineral deposition in vitro. However, the current findings are similar to a report that DHA does not affect osteoblast differentiation and metabolism in vitro (37). The differences in the effects of DHA on osteoblast mineralisation in vitro could be due to the cell line used as well as the concentration and time of administration of this omega- 3 fatty acid. 


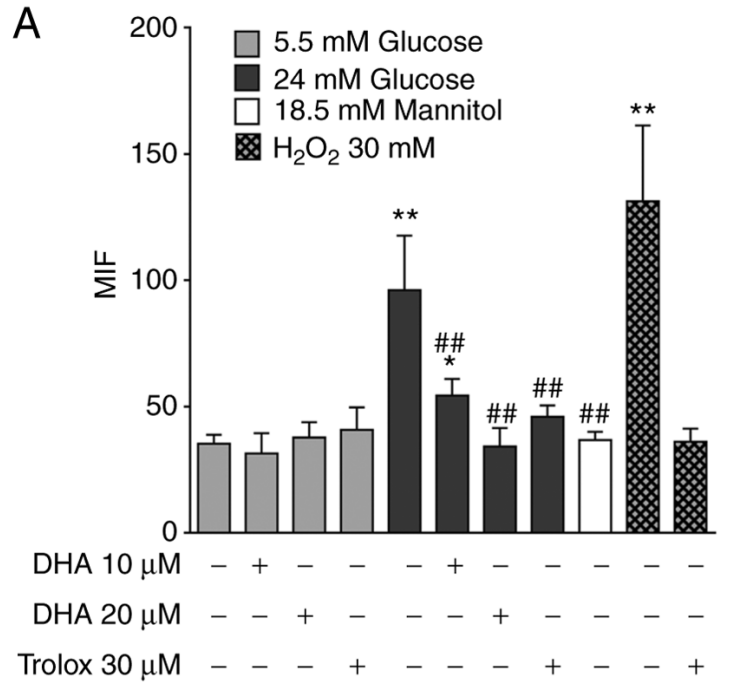

B

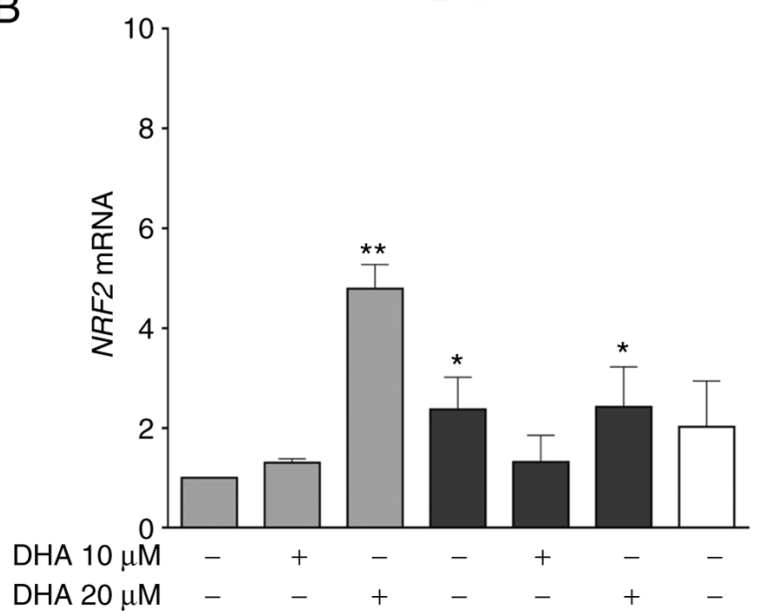

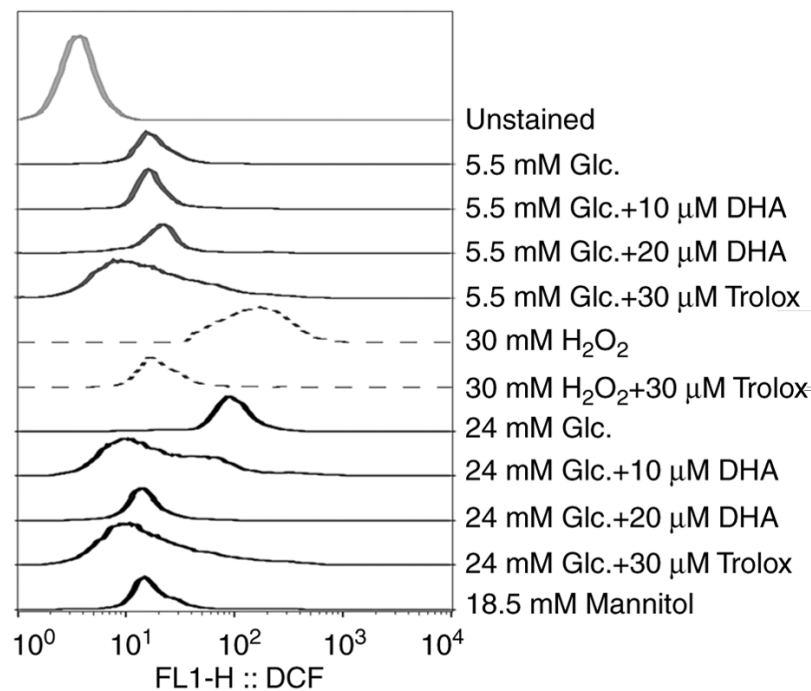

7 days

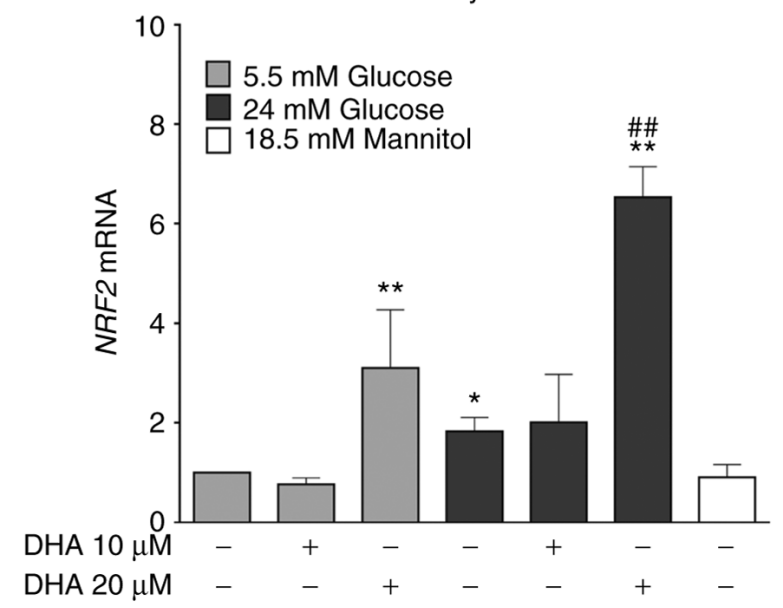

Figure 6. Effect of DHA with 5.5 or $24 \mathrm{mM}$ glucose concentrations on oxidative stress caused by 24 mM glucose. (A) Results of intracellular measurement of reactive oxygen species by flow cytometry using the DCF fluorescent probe. MFI graphs and histograms representative of the results obtained are shown. (B) Effect of DHA on the expression of NRF2 mRNA in the presence of different glucose concentrations. All graphs represent the mean \pm SD. ${ }^{*}<0.05$ and ${ }^{* *} \mathrm{P}<0.01$ vs. control (5.5 mM glucose); ${ }^{\# \#} \mathrm{P}<0.01$ vs. $24 \mathrm{mM}$ glucose. DHA, docosahexaenoic acid; DCF, 2'7'-Dichlorofluorescein; MFI, median fluorescence intensity; NRF2, nuclear factor erythroid 2-related factor-2.

In the present study, $\mathrm{HG}$ increased calcium deposition at days 14 and 21 of culture (Fig. 4B), which is likely due to a combination of hyperosmotic stress and glucose. Still, only HG decreased the quality of the mineral deposit by osteoblasts, evidenced by an increase in the carbonate/phosphate ratio (Table II) (32). The decreased BSP-II expression in osteoblasts cultured in HG (Fig. 2) may be due to the inhibition of HAP crystal enucleation. Consequently, $\mathrm{HG}$ causes an accumulation of calcium phosphate and hyper-calcification of the extracellular matrix, but the HAP crystals are less pure and, consequently, more fragile.

The high strength and fracture toughness in the bone matrix are also due to the collagen scaffold. HG increased the concentration and disordered distribution of Coll (Fig. 1A). Cunha et al (38) also reported that HG induces an excess of organic matrix in bone. High collagen production associated with disorganised deposition could be a consequence of nonenzymatic glycation (39). The formation of advanced glycation end products is associated with changes in bone microarchitecture, which, together with the decrease in mineral bone quality, could trigger fragile bones and increase the risk of fracture, as observed in patients with DM2 $(40,41)$.

HG induces oxidative stress in osteoblasts (9). Consistently, the current study observed that HG increased ROS production (Fig. 6A). Previous reports have proposed that oxidative stress mediated by the phosphoinositide 3-kinase (PI3K)/Akt pathway may be one of the main causes of alterations in biomineralization, osteoblast metabolism and bone remodelling $(9,42)$, as was observed in the present study in the synthesis of OCN (Fig. 1B and C), ALP specific activity (Fig. 3), BSP-II expression (Fig. 2) and HAP crystal formation and quality (Figs. 4 and 5).

Culturing hFOB 1.19 cells in HG and treating with DHA improved the distribution of Col1 protein and increased its concentration in the scaffold formation (Fig. 1A). A previous report indicated that DHA has anabolic effects on the formation of the extracellular matrix (20). The improved distribution of Col1 mediated by DHA could be related to a decrease in collagen glycation. 


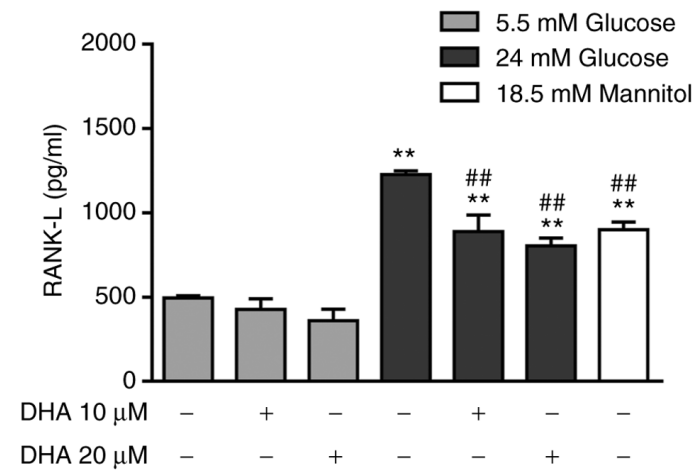

Figure 7. Effect of DHA with 5.5 or $24 \mathrm{mM}$ glucose concentrations on the extracellular production of RANK-L. The graph represents the mean \pm SD of three independent experiments. ${ }^{* *} \mathrm{P}<0.01$ vs. control ( $5.5 \mathrm{mM}$ glucose); ${ }^{\# \#} \mathrm{P}<0.01$ vs. $24 \mathrm{mM}$ glucose. DHA, docosahexaenoic acid; RANK-L, receptor activator of nuclear factor $\kappa-\beta$ ligand.

Of note, DHA treatment in cells cultured in HG showed promising effects; it normalised calcification, HAP crystal quality, ALP activity, and OCN, BSP-II and Coll expression (Figs. 1-5 and Table II). These effects may be associated with the reported effects of omega-3 fatty acids on enhancing ALP gene expression by decreasing prostaglandin E2 $\left(\mathrm{PGE}_{2}\right)$ production through an as yet undetermined mechanism (20). Curiously, in the current study cells cultured in HG and treated with $20 \mu \mathrm{M}$ DHA showed a time-dependent increase in ALP activity, which may be reflected in a slower or a slightly delayed mineralisation that allows correct formation of bone matrix with the proper proportion of HAP crystals in the organic and inorganic mineral matrices.

Sharma et al (43) proposed that omega-3 fatty acids could negatively regulate abnormal microcalcification by modulating PI3K/AKT/extracellular signal-regulated kinase (ERK) signalling to inhibit expression of osteoblastic transcription factors RUNX2, osterix and Msx2, which could be upregulated by bone morphogenetic protein 2 (43). These fatty acids could also help in bone preservation and reduce the risk of osteoporosis by increasing AKT, mitogen-activated protein kinase and ERK signalling in osteoblasts to increase the differentiation and calcification of bone (44).

The observations of the present study demonstrated that culturing osteoblasts in HG and treating them with DHA improved the mineral matrix synthesis and their organic matrix components. Moreover, regarding relative mineralisation, which is related to bone strength and mineral distribution, DHA promoted homogeneous mineralisation of the osteoblast matrix (Fig. 4A) and a decrease in the carbonate/phosphate ratio, indicating an increase in the HAP crystal quality (Fig. 5C). To the best of our knowledge, this is the first report of the effect of DHA on the quality of HAP crystals formed by osteoblasts cultured in HG. The effect of DHA on biomineralization of osteoblasts cultured in HG could be related to its antioxidant effects. HG induces oxidative stress in rat primary osteoblasts as one of the main causes of altered biomineralization, osteoblast metabolism and bone remodelling $(9,42)$. DHA has antioxidant effects in vascular endothelial cells under the stimulus of IL-1 $\alpha$ (45). In addition, Richard et al (12) reported that omega-3 fatty acids could trap free radicals.
For the first time, the current study observed the DHA-mediated inhibition of HG-induced ROS production as an antioxidant effect in an osteoblast cell line (Fig. 6A). This mechanism possibly involves activating the NRF2/HO-1 antioxidant pathway. Of note, DNA activates this pathway in EA.hy926 cells (14). The ROS reduction that was observed in the present study following DHA treatment could be mediated via the NRF2 pathway as DHA increased NRF2 expression, which had been reduced due to HG (Fig. 6). It should be noted that the effects of DHA on the expression of NRF2 seem to be dependent on its concentration; $20 \mu \mathrm{M}$ DHA increased NRF2 expression more in either $\mathrm{NG}$ or $\mathrm{HG}$, whereas the effect of $10 \mu \mathrm{M}$ DHA was not as notable.

DHA is a potent inhibitor of osteoclast differentiation in RAW 264.7 cells (46). Therefore, RANK-L production after DHA treatment was analysed. It was found that the effect of $\mathrm{HG}$ on RANK-L production is a combination of $\mathrm{HG}$ and hyperosmolarity, because the iso-osmotic control (18.5 mM Man) also increased RANK-L production (Fig. 7). Adding DHA to osteoblasts cultured in HG decreased RANK-L overproduction (Fig. 7). This effect may be due to the anti-inflammatory effects of this fatty acid, as have been reported in MC3T3-E1/4 osteoblasts cultured with $\mathrm{PGE}_{2}$ (47). Therefore, DHA may decrease osteoclastogenesis and bone resorption in the presence of $\mathrm{HG}$.

In conclusion, treatment with $20 \mu \mathrm{M}$ DHA counteracted the adverse effects of HG in the organic and inorganic bone mineral matrix and improved the quality of the crystals, likely by decreasing oxidative stress and increasing the expression of NRF2 in human osteoblasts. It is important to continue studying the antioxidant mechanisms of DHA in osteoblasts cultured in HG. These results suggested that DHA could be used as an adjuvant treatment for diabetic osteopathy. Experiments involving animal models of DM2, and clinical trials are necessary to investigate this possibility in more detail.

\section{Acknowledgements}

The authors would like to acknowledge Dr Maria Cristina Zorrilla Cangas (Advanced Materials Laboratory, Physics Institute, National Autonomous University of Mexico) for her assistance and technical support in scanning electron microscopy and Dr Marco Antonio Alvarez Perez (Bioengineering Laboratory, Dentistry Faculty, National Autonomous University of Mexico) for providing the fourier-transform infrared spectroscopy equipment.

\section{Funding}

This study was supported by Programa de Apoyo a Proyectos de Investigación Tecnológica/Dirección General de Asuntos del Personal Académico/Universidad Nacional Autónoma de México (PAPIIT/DGAPA/UNAM; grant no. IN223619).

\section{Availability of data and materials}

The datasets used and/or analyzed during the current study are available from the corresponding author on reasonable request. 


\section{Authors' contributions}

LMF and ALGH conceived and designed the study. SECM, ALGH and PGA acquired the data. LMF, SECM, ALGH and PGA were responsible for the analysis and interpretation of data. LMF, SECM, ALGH and PGA drafted the manuscript. SECM and ALGH confirm the authenticity of all the raw data. All authors have read and approved the final manuscript.

\section{Ethics approval and consent to participate}

Not applicable.

\section{Patient consent for publication}

Not applicable.

\section{Competing interests}

The authors declare that they have no competing interests.

\section{References}

1. Kerner W and Brückel J; German Diabetes Association: Definition, classification and diagnosis of diabetes mellitus. Exp Clin Endocrinol Diabetes 122: 384-386, 2014.

2. International Diabetes Federation: IDF diabetes atlas eighth edition, 2017.

3. Farr JN and Khosla S: Determinants of bone strength and quality in diabetes mellitus in humans. Bone 82: 28-34, 2016.

4. Carnevale V, Romagnoli E, D'Erasmo L and D'Erasmo E: Bone damage in type 2 diabetes mellitus. Nutr Metab Cardiovasc Dis 24: 1151-1157, 2014.

5. Hofbauer LC, Brueck CC, Singh SK and Dobnig H: Osteoporosis in patients with diabetes mellitus. J Bone Miner Res 22: 1317-1328, 2007.

6. Hamann C, Kirschner S, Günther KP and Hofbauer LC: Bone, sweet bone-osteoporotic fractures in diabetes mellitus. Nat Rev Endocrinol 8: 297-305, 2012.

7. Bonds DE, Larson JC, Schwartz AV, Strotmeyer ES, Robbins J, Rodriguez BL, Johnson KC and Margolis KL: Risk of fracture in women with type 2 diabetes: The women's health initiative observational study. J Clin Endocrinol Metab 91: 3404-1310, 2006.

8. García-Hernández A, Arzate H, Gil-Chavarría I, Rojo R and Moreno-Fierros L: High glucose concentrations alter the biomineralization process in human osteoblastic cells. Bone 50: 276-288, 2012

9. Zhang Y and Yang JH: Activation of the PI3K/Akt pathway by oxidative stress mediates high glucose-induced increase of adipogenic differentiation in primary rat osteoblasts. J Cell Biochem 114: 2595-2602, 2013.

10. Arai M, Shibata Y, Pugdee K, Abiko Y and Ogata Y: Effects of reactive oxygen species (ROS) on antioxidant system and osteoblastic differentiation in MC3T3-E1 cells. IUBMB Life 59: 27-33, 2007.

11. Bai XC, Lu D, Bai J, Zheng H, Ke ZY, Li XM and Luo SQ Oxidative stress inhibits osteoblastic differentiation of bone cells by ERK and NF-kappaB. Biochem Biophys Res Commun 314: 197-207, 2004

12. Richard D, Kefi K, Barbe U, Bausero P and Visioli F: Polyunsaturated fatty acids as antioxidants. Pharmacol Res 57: 451-455, 2008

13. Rotstein NP, Politi LE, German OL and Girotti R: Protective effect of docosahexaenoic acid on oxidative stress-induced apoptosis of retina photoreceptors. Invest Ophthalmol Vis Sci 44: 2252-2259, 2003.

14. Yang YC, Lii CK, Wei YL, Li CC, Lu CY, Liu KL and Chen HW: Docosahexaenoic acid inhibition of inflammation is partially via cross-talk between Nrf2/heme oxygenase 1 and IKK/NF- $\mathrm{KB}$ pathways. J Nutr Biochem 24: 204-212, 2013.
15. Darlington LG and Stone TW: Antioxidants and fatty acids in the amelioration of rheumatoid arthritis and related disorders. $\mathrm{Br}$ J Nutr 85: 251-269, 2001.

16. Högström M, Nordström P and Nordström A: n-3 Fatty acids are positively associated with peak bone mineral density and bone accrual in healthy men: The NO2 study. Am J Clin Nutr 85: 803-807, 2007.

17. Fallon EM, Nazarian A, Nehra D, Pan AH, O'Loughlin AA, Nose V and Puder M: The effect of docosahexaenoic acid on bone microstructure in young mice and bone fracture in neonates. J Surg Res 191: 148-155, 2014.

18. Farahnak Z, Freundorfer MT, Lavery P and Weiler HA: Dietary docosahexaenoic acid contributes to increased bone mineral accretion and strength in young female sprague-dawley rats. Prostaglandins Leukot Essent Fatty Acids 144: 32-39, 2019.

19. Atkinson TG, Barker HJ and Meckling-Gill KA: Incorporation of long-chain n-3 fatty acids in tissues and enhanced bone marrow cellularity with docosahexaenoic acid feeding in post-weanling fischer 344 rats. Lipids 32: 293-302, 1997.

20. Watkins BA, Li Y, Lippman HE and Feng S: Modulatory effect of omega-3 polyunsaturated fatty acids on osteoblast function and bone metabolism. Prostaglandins Leukot Essent Fatty Acids 68: 387-398, 2003.

21. Kim HJ, Ohk B, Yoon HJ, Kang WY, Seong SJ, Kim SY and Yoon YR: Docosahexaenoic acid signaling attenuates the proliferation and differentiation of bone marrow-derived osteoclast precursors and promotes apoptosis in mature osteoclasts. Cell Signal 29: 226-232, 2017.

22. Coetzee M, Haag M and Kruger MC: Effects of arachidonic acid and docosahexaenoic acid on differentiation and mineralization of MC3T3-E1 osteoblast-like cells. Cell Biochem Funct 27: 3-11, 2009.

23. Moskot M, Jakóbkiewicz-Banecka J, Kloska A, Piotrowska E, Narajczyk M and Gabig-Cimińska M: The role of dimethyl sulfoxide (DMSO) in gene expression modulation and glycosaminoglycan metabolism in lysosomal storage disorders on an example of mucopolysaccharidosis. Int J Mol Sci 20: 304, 2019.

24. Maurin AC, Chavassieux PM, Vericel E and Meunier PJ: Role of polyunsaturated fatty acids in the inhibitory effect of human adipocytes on osteoblastic proliferation. Bone 31: 260-266, 2002.

25. Gregory CA, Gunn WG, Peister A and Prockop DJ: An Alizarin red-based assay of mineralization by adherent cells in culture: Comparison with cetylpyridinium chloride extraction. Anal Biochem 329: 77-84, 2004.

26. Tullberg-Reinert $\mathrm{H}$ and Jundt $\mathrm{G}$ : In situ measurement of collagen synthesis by human bone cells with a sirius red-based colorimetric microassay: Effects of transforming growth factor beta2 and ascorbic acid 2-phosphate. Histochem Cell Biol 112: 271-276, 1999.

27. Bradford MM: A rapid and sensitive method for the quantitation of microgram quantities of protein utilizing the principle of protein-dye binding. Anal Biochem 72: 248-254, 1976.

28. Romero-Calvo I, Ocón B, Martínez-Moya P, Suárez MD, Zarzuelo A, Martínez-Augustin O and de Medina FS: Reversible ponceau staining as a loading control alternative to actin in western blots. Anal Biochem 401: 318-320, 2010.

29. Wrobel E, Leszczynska J and Brzoska E: The characteristics of human bone-derived cells (HBDCS) during osteogenesis in vitro. Cell Mol Biol Lett 21: 26, 2016.

30. Bourrat C, Radisson J, Chavassieux P, Azzar G, Roux B and Meunier PJ: Activity increase after extraction of alkaline phosphatase from human osteoblastic membranes by nonionic detergents: Influence of age and sex. Calcif Tissue Int 66: 22-28, 2000.

31. Buell MV, Lowry OH, Roberts NR, Chang ML and Kapphahn JI: The quantitative histochemistry of the brain. V. Enzymes of glucose metabolism. J Biol Chem 232: 979-993, 1958.

32. Figueiredo MM, Gamelas JAF and Martins AG: Characterization of bone and bone-based graft materials using FTIR spectroscopy. In: Infrared Spectroscopy-Life and Biomedical Sciences, Theophile T (ed). IntechOpen, 2012.

33. Rio DC, Ares M Jr, Hannon GJ and Nilsen TW: Purification of RNA using TRIzol (TRI reagent). Cold Spring Harb Protoc 2010: pdb.prot5439, 2010.

34. Livak KJ and Schmittgen TD: Analysis of relative gene expression data using real-time quantitative PCR and the 2(-Delta Delta C(T)) method. Methods 25: 402-408, 2001.

35. Manolagas SC: From estrogen-centric to aging and oxidative stress: A revised perspective of the pathogenesis of osteoporosis. Endocr Rev 31: 266-300, 2010. 
36. He F, Ru X and Wen T: NRF2, a transcription factor for stress response and beyond. Int J Mol Sci 21: 4777, 2020.

37. Casado-Díaz A, Santiago-Mora R, Dorado $G$ and Quesada-Gómez JM: The omega-6 arachidonic fatty acid, but not the omega-3 fatty acids, inhibits osteoblastogenesis and induces adipogenesis of human mesenchymal stem cells: Potential implication in osteoporosis. Osteoporos Int 24: 1647-1661, 2013.

38. Cunha JS, Ferreira VM, Maquigussa E, Naves MA and Boim MA: Effects of high glucose and high insulin concentrations on osteoblast function in vitro. Cell Tissue Res 358: 249-256, 2014.

39. Shi P, Liu H, Deng X, Jin Y, Wang Q, Liu H, Chen M and Han X: Label-free nonenzymatic glycation monitoring of collagen scaffolds in type 2 diabetic mice by confocal Raman microspectroscopy. J Biomed Opt 20: 27002, 2015.

40. Vestergaard P: Discrepancies in bone mineral density and fracture risk in patients with type 1 and 2 diabetes-a meta-analysis. Osteoporos Int 18: 427-444, 2007.

41. Yamamoto M: Insights into bone fragility in diabetes: The crucial role of bone quality on skeletal strength. Endocr J 62: 299-308, 2015.

42. Wauquier F, Leotoing L, Coxam V, Guicheux J and Wittrant $Y$ : Oxidative stress in bone remodelling and disease. Trends Mol Med 15: 468-477, 2009

43. Sharma T, Sharma A, Maheshwari R, Pachori G, Kumari P and Mandal CC: Docosahexaenoic acid (DHA) inhibits bone morphogenetic protein-2 (BMP-2) elevated osteoblast potential of metastatic breast cancer (MDA-MB-231) cells in mammary microcalcification. Nutr Cancer 72: 873-883, 2020.
44. Mao L, Wang M,Li Y,Liu Y, Wang J and Xue C: Eicosapentaenoic acid-containing phosphatidylcholine promotes osteogenesis: Mechanism of up-regulating Runx 2 and ERK-mediated phosphorylation of PPAR $\gamma$ at serine 112. J Funct Foods 52: 73-80, 2019.

45. Massaro M, Habib A, Lubrano L, Del Turco S, Lazzerini G, Bourcier T, Weksler BB and De Caterina R: The omega-3 fatty acid docosahexaenoate attenuates endothelial cyclooxygenase-2 induction through both NADP $(\mathrm{H})$ oxidase and PKC epsilon inhibition. Proc Natl Acad Sci USA 103: 15184-15189, 2006.

46. Rahman MM,Bhattacharya A and Fernandes G: Docosahexaenoic acid is more potent inhibitor of osteoclast differentiation in RAW 264.7 cells than eicosapentaenoic acid. J Cell Physiol 214: 201-209, 2007.

47. Poulsen RC, Wolber FM, Moughan PJ and Kruger MC: Long chain polyunsaturated fatty acids alter membrane-bound RANK-L expression and osteoprotegerin secretion by MC3T3-E1 osteoblast-like cells. Prostaglandins Other Lipid Mediat 85: 42-48, 2008.

This work is licensed under a Creative Commons Attribution-NonCommercial-NoDerivatives 4.0 International (CC BY-NC-ND 4.0) License. 